malarial or cardiac form-was not clearly shown; but the influence of a previously damaged aortic valve in the production of the disease was manifest, a fact to be remembered in life assurance examinations. The case unhappily progressed from the first to its fatal end little influenced by the treatment used. The record as to the efficacy of anti-streptococcic serum and nuclein is therefore a negative one, but inasmuch as these remedies received a thorough trial the facts are now published. So far as the experience of a single case goes it points to the uselessness of the serum when no streptococci, but only staphylococci, are found in the blood. In connexion with this it may be noted that a Russian physician has reported a case of malignant endocarditis treated successfully with antistaphylococcic serum. ${ }^{1}$ The marked, although temporary, benefit derived from free minute pustulation is noteworthy and brings to mind the "counter-stimulant" use of tartar emetic which was introduced by Dr. Edward Jenner and so extensively practised for all inflammatory diseases during the earlier half of this century. In the present case there were micrococci, toxins, and much hot inflammatory material circulating in the blood, and those who watched the patient during the pustulation and noted his declining pyrexia and general increased comfort for the time being, could not resist the inference that the pustules actually withdrew some of the noxious matter from the circulation. The patienc had also the advantage of the advice of Sir William Gowers, of Dr. Arthur Davies, and of Mr. A. H. Tubby, who saw him at various stages of his illness. The bacteriological examinations were made by the Jenner Institute of Preventive Medicine and the Clinical Research Association, whose reports agreed very closely.

\section{A CASE OF PREGNANCY OCCURRING IN A PATIENT WITH A DOUBLE UTERUS AND A DOUBLE VAGINA.}

\section{By C. J. GLASSON, M.D. BRUX, L.R.C.P. LoND.,} M.R C.S. ENG.

IN reporting this case I have done so that it may add to the few cases which are on record.

On the evening of Sept. 3rd, 1899, I was called to attend a primipara, aged 21 years, in her confinement. On my arrival at the house I found that she had been in labour for some hours and that the pains were getting very strong, but that the child did not seem to get any lower. The liquor amnii had burst some time before during one of the pains. The woman was walking about when I got to the house. I placed her on the bed and proceeded to examine her in order to find out the presentation, but to my surprise I could not feel the child's head exc oting through a thick membrane. At first I thought that I must have made a mistake and inserted my finger in the rectum, but I could feel the anus distinctly with my left index finger. I got my finger as high as I could possibly get it, but could not feel the os or the uterus. I withdrew my finger and re-inserted it; this time there was no mistake, for I could feel the child's head distinctly in the first position. The head had come through the os and was pressing down hard upon a thick band. There was no deformity of the pelvis either at the inlet or the outlet; in fact, there was plenty of room. I proceeded to examine her more carefully by the aid of a good lamp and upon separating the folds of the vulva I could distinctly feel and "see" a thick septum extending anteriorly and posteriorly across the vagina. I easily passed $m y$ index finger into the right side but felt no os, and again into the left vagina and felt the child's head. I passed my finger up along the whole of the septum until I came to its junction with the uterus. All the parts were, of course, congested and swollen as is usual at labour. While I was examining her during one of the pains, which were now becoming exceedingly powerful, I could feel the child's head pressing upon and throwing the septum into a fold which by stretching across the head prevented its coming down any further. Just before this pain tinished the patient complained that something had given way inside her and the pain suddenly ceased. I found, upon examination, that the upper portion of the septum had given way and that there was now a foramen through which

1 Brit. Med. Jour. Epitome, July 2nd, 1898, art. 12.
I could pass my finger into the right vagina. When the next pain came on I had been holding the septum to the right side of the vagina, so that, if possible, the child's head might slip through. This I was enabled to manage after a good deal of manipulation and had the satisfaction of getting the head safely past the obstruction. Soon the child's head was weli down on the perineum and while a stronger pain than usual was on the patient felt something more give way. This was the septum at its lower attachments. After that $I$ had no further trouble. The head was born, then the shoulders and the rest of the body. The child was a big male child and weighed, I should judge, between seven and eight pounds. There was a distinct mark across the head where the fold of the septum had pressed. I expressed the placenta and there was very little hæmorrhage. I examined the patient carefully after the placenta had come away and I could feel and see where the septum had been torn away and could feel the septum still whole up to the uterus except where the hole had been torn through close to the os. I could also feel high up on the right side a mass but could not make out definitely what it was. The perineum itself was intact. The patient made a splendid recovery and got up on the twelfth day.

I questioned the patient's mother concerning her, but she said that she had never noticed anything wrong. I asked the patient about her menses; these, she said, had been irregular, they had occurred once in tive or six weeks, and then they had been very scanty and had lasted about two days. She never menstruated after marriage and the baby was born 10 months after that event. I asked if ber husband had had any difficulty during intercourse. She replied in the negative, but that sometimes there had been some apparent obstruction, but of this she bad taken no notice. Four weeks after labour I made a thorough examination. Externally the vulva and labia were normal. The urethra, the anus, and the rectum were normal, but I could easily see by separating the labia where the septum had been attached in front along the median line at the base of the bladder and behind to the median line in front of the rectum, and on tracing the remains up I could feel where it became continuous with the part of the septum that was still whole. On passing the finger up into the left vagina I could feel the uterus which had regained its normal size, and bimanually I could feel the fundus which was pointing to the left side. I then passed my finger into the right vagina and there I found another uterus of about the size of the first one with its fundus pointing to the right side and between the two I could pass my finger up and touch my fingers placed externally. I could only feel one ovary on each side and none between. I did not examine her per rectum. The following diagram will explain the conditions found. I should add that the vaginal septum passed upward and was continuous with the septum between the two uteri.

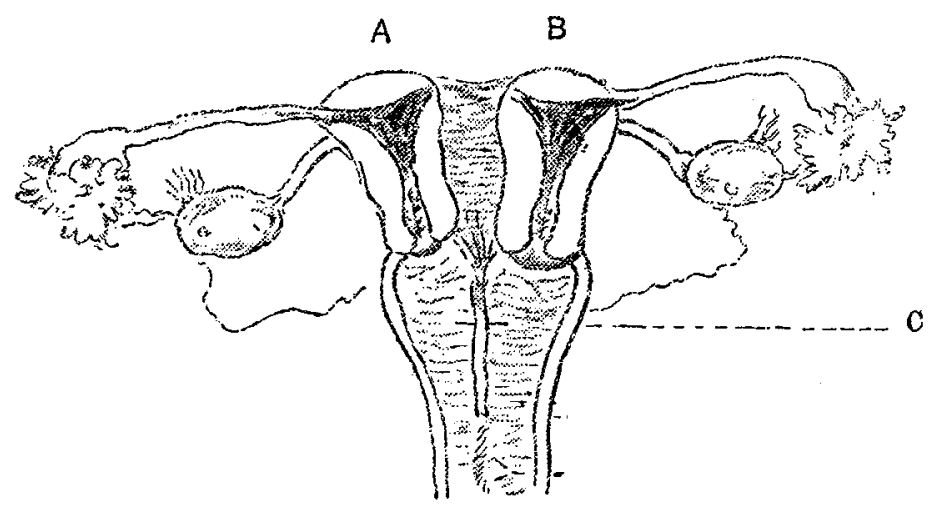

A, right uterus ; $B$, left uterus, in which pregnanuy occurred. C, Foramen at upper part of septum.

This is a rare case of abnormal development and one in which very serious trouble might bave arineu in the course of labour. Had there not been plenty of room to manipulate the band formed by the septum it would have had to be divided. I was exceedingly glad that I had to do no such thing, partly on account of the hæmorrhage that might have followed and partly on account of the smallness of the space to work in and the damage which might have been done by the knife when the pains were so frequent and of such a strong character. I have been trying to persuade the patient to undergo an operation for the removal of the septum, but neither she nor her husband will consent to anything being done, so for the present the conditions must remain in statu quo.

Chadwell Heath, Essex. 


\section{IDIOPATHIC PERFORATION OF THE BONES OF THE NASAL SEPTUM.}

\section{BY W. J. O. MERRY, M.A., M.D., B.CH. OXON.}

IDIOPATHIC perforation of the cartilaginous portion of the nasal septum is not uncommon; it is, however, but rarely allowed that ulcerative perforation through the vomer or perpendicular ethmoidal plate can have other than a specific cause. That superficial necrosis of the nasal bones may follow on prolonged local inflammation of a simple nature is well known, and often exemplified in the course of the formation of a mucous polypus, but I am unable to find a record of a case of this kind resulting in the extensive perforation which I have endeavoured to describe below. The possibility of syphilitic infection in this case was most carefully gone into, but there were absolutely no evidences of either previous or present specific lesions in either husband, wife, or children. The following is a brief account of the bistory of the case.

A lady of good family, aged 40 years, consulted a leading specialist in the summer of 1898 about the difficulty she had in nasal respiration, and $I$ am indebted to him for the following short account of the condition of the nares at that time. The septum was then much deflected towards the left and in contact with the inferior turbinate bone on that side, the mucous membrane covering which was hypertrophied. The right nostril was apparently normal. Removal of a portion of the septum was strongly advised, but this the patient refused to have done. The hypertrophied mucous membrane was then treated with the galvanic cautery and a narrow space was obtained in this way between the septum and the outer wall. At the end of this treatment nasal respiration was unobstructed, which relief persisted for four or five months. After a severe coryza in December, however, the obstruction returned and remained. During the first half of 1899 the patient suffered frequently from coryza, but it was not until May that any foetor was noticed. At this time, also, a creamy purulent discharge commenced, which formed troublesome crusts in the nostril. For the alleviation of this the patient used, by advice, antiseptic nasal sprays and iodide of potassium internally, but without benefit. In July she consulted me and on examination the left nostril was seen to be plugged with a mass of pale, soft granulation tissue, which bled readily on being touched and was very friable and insensitive. The whole nostril, so far as could be seen, was bathed in a purulent exudation, but there was at this time but little foetor, though the patient herself complained of a bad smell in the nose. In the right nostril there was a small amount of purulent discharge and the mucous membrane covering the inferior turbinate bone was hypertrophied. The mucous membrane of the septum was normal save for a small mass of granulation tissue which was afterwards found to correspond with the perforation in its wall. Anterior rhinoscopy was at that time of little further use, but a probe detected a spot of bare bone on the edge of the inferior turbinate bone on the left.

After rendering the nostrils as antiseptic as the conditions allowed, the mass of granulation tissue in the left nostril was removed with a sharp spoon under cocaine anæsthesia Hæmorrhage, which was sharp at first, ceased as the nostril became clear. In the course of the operation it was noticed that the septum was perforated. The removed tissue revealed nothing on examination further than ordinary granulation tissue and contained no fragments of bone. No sequestrum had been noticed at any time during the progress of the disease, which had been entirely painless throughout. A good view could now be obtained and it was seen that the perforation included portions of the vomer and perpendicular plate of the ethmoid. The edges of the perforation were soft carious bone embedded in inflamed mucous membrane. In the further progress of the case, details of which are here unnecessary, these edges became gradually covered as the mucosa became healthy, there being but little further loss of bone. At the end of six weeks the lining membrane had regained a normal healthy aspect and the margins of the perforation, which was of the size of a shilling, had become entirely covered, with the exception of one small spot in the upper segment.

The only treatment adopted after the operation was local and consisted of sprays of menthol in liquid vaseline and an antiseptic nasal douche. A 1 in 20 solution of phenol was also applied twice a week on some cotton-wool on the end of a probe. The perforation causes the patient no inconvenience, the nasal respiration is unimpeded, and there is no external deformity.

The explanation of the case seems to be as follows. Consequent on the repeated coryza the nasal mucosa became swollen and hyperæmic and contact between the two sides of the left nostril became again established, as was the case before the original cauterisation. The continued pressure thus exercised between the surfaces of this swollen and chronically inflamed mucous membrane, with its resistance thereby lowered, gave rise in due course to superficial molecular necrosis of the mucosa. This ulcerative process, once started, in tissue of low vitality and with the exudation unable to drain away freely, might readily extend and, by destroying the muco-periosteum, give rise to caries of the subjacent bone. The blame cannot be ascribed to the operation of cauterisation, the immediate effects of which were admitted as beneficial by the patient and only annulled by the chronic catarrh which commenced some four months after. A factor which can but have aided the process was the employment by the patient of a hairpin wrapped in cotton-wool to remove the crusts which were formed in the nostril by the dried exudation. That the perforation may have been caused by osteoclasts is another possible, though less likely, explanation, but one which I am not in this case in a position to prove or dispreve.

Eastbourne.

\section{TWO CASES OF DEATH UNDER CHLOROFORM.}

By J. M. ATKINSON, M.B. LOND., PRINCIPAL-CIVII MEDICAL OFFICER, HONG-KONG; AND

J. BELL, M.R.C.S. ENG., L.R.C.P. LoND. ASSISTANT SUPERINTENDENT, GOVERNMENT CIVIL HOSPITAL, HONG-KONG.

CASE 1.-The patient, a woman, aged 25 years, a European, was sent to the Government Civil Hospital, Hong-Kong, by Dr. Jordan in order to be examined under chloroform as she was suffering from some uterine tronble complicated with an abdominal tumour. She was admitted at 4 P.M. on August 9th last and on that evening she was given an aperient followed by an enema on the morning of the 10th. She had a cup of tea for breakfast on that day and a glass of milk at 11 A.M. The patient had had four children. In May last there was an attack of hæmorrhage from the uterus which under treatment ceased in a few days. Since then her menses bad ceased and latterly her abdomen had been increasing in size. On superficial examination there was seen to be a swelling in the right lumbar region continuous with the liver dulness. Dr. Jordan had examined her heart and had found it to be normal. The patient told Dr. Atkinson that she had taken chloroform before some two years ago for, Dr. Atkinson believes, extraction of some teeth. At 1.7 P.M. on the 10th Dr. Atkinson commenced to give chloroform with Krohne and Sesemann's regulating inhaler which had been in use at this hospital since October last, Dr. Jordan taking the patient's pulse. As she struggled slightly the mask was removed from her face for a few seconds and then replaced, the bellows being only slightly compressed. In a few minutes the conjunctive were insensitive and Dr. Atkinson said that she could be examined. On looking at the watch it was $1.10 \frac{1}{2}$ P.M. Dr. Jordan commenced to manipulate the tumour when he remarked to Dr. Atkinson that the muscles were not fully relaxed. The administration of chloroform was being continued when in a few seconds the patient suddenly gasped; the mask was removed at once when she was seen to be cyanosed and her pulse could not be felt. Artificial respiration was at once commenced, the patient's tongue being pulled forward, and kept up until 1.40 P.M. Sirychnine was injected, sponges dipped in hot water were applied to the præcordium, nitrite of amyl was 